\title{
Hydrodynamic ram analysis of aircraft fuel tanks with different composite $T$-joint designs
}

\author{
S. Heimbs ${ }^{1}$, T. Duwensee ${ }^{1}$, A. C. Nogueira ${ }^{1} \&$ J. Wolfrum ${ }^{2}$ \\ ${ }^{1}$ Airbus Group Innovations (formerly EADS Innovation Works), \\ Munich, Germany \\ ${ }^{2}$ WIWeB, Bundeswehr Research Institute for Materials, Fuels and \\ Lubricants, Germany
}

\begin{abstract}
Three different composite T-joint designs were investigated experimentally and numerically for application in fuel-filled wing tanks under hydrodynamic ram (HRAM) loads. The test campaigns covering $0^{\circ} \mathrm{T}$-pull and $30^{\circ} \mathrm{T}$-bending tests were conducted under quasi-static and high-rate dynamic conditions in order to assess potential strain rate effects on the failure behaviour. In addition to the experimental test campaign, numerical modelling with the explicit finite element code LS-Dyna was conducted with the models being validated against the test results and being applied to ballistic impact simulations of a composite fuelfilled tank structure. While the unreinforced baseline design showed a rather brittle behaviour and poor performance, significant residual strength improvements and structural integrity under HRAM loads could be obtained with a hybrid design with metallic, arrow-shaped z-reinforcements between the composite laminates of skin and spar. A promising macro modelling approach for an efficient representation of the T-joint failure behaviour in large models was derived and successfully applied to structural HRAM simulations.

Keywords: composite T-joint, hydrodynamic ram, ballistic impact simulation.
\end{abstract}

\section{Introduction}

The focus of this research study is on composite T-joints as a typical connection found in aircraft wing structures and integral tanks. Fuel-filled tanks may be susceptible to a load case that is called hydrodynamic ram (HRAM), which is the result of a ballistic impact and projectile penetration through the outer skin into 
the fuel. The shock front that develops and propagates inside the fluid may lead to very high pressures acting on the tank structure with potential structural damage [1-7]. Typical locations for damage are the structural T-joint connections between skin and spar [8-10].

The aim of this study was to investigate the failure behaviour of different composite T-joint designs in fuel tanks under HRAM loading. T-samples of different designs were manufactured and tested under quasi-static and high-rate dynamic loads in order to characterise the failure behaviour and to validate numerical models in LS-Dyna. The models were used in HRAM simulations of fluid-filled tanks in order to compare their structural performance and damage resistance under different load cases.

\section{T-joint design, manufacturing and testing}

\subsection{Composite T-joint designs}

The failure behaviour of three different composite $\mathrm{T}$-joint designs was assessed in this study. The reference design D1 is a state-of-the-art design that can be found in various aircraft structures. It consists of a spar, which splits into two distinct spar feet that are connected to the skin by co-curing (Figure 1a)). The second design D2 is a slight modification or improvement with the spar feet having no specific edge but continuing to the next spar, forming an integral part of the skin (Figure 1b)). Although this design is not expected to increase the damage initiation load, it is intended to enable higher energy absorption under tensile loads by a higher delamination surface and to enable structural integrity and leak tightness in a fuel tank application.

The third design D3 includes a metallic z-reinforcement concept to increase the connection between spar feet and skin. Such hybrid joints using metallic sheets with reinforcement pins connecting carbon fibre laminates were investigated in different recent studies with the arrow-shaped metallic pins leading to a strong mechanical interlocking effect within the composite laminate. For this reason, the metal pin-reinforcement approach was also selected to be studied here, making use of formed, spiked metal sheet inserts described in [11, 12] (Figure 1c)).
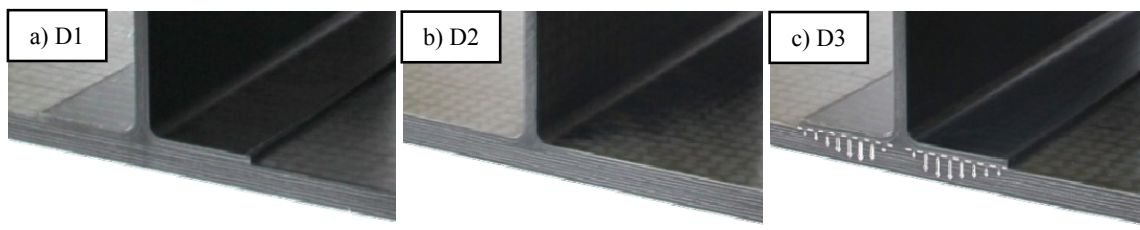

Figure 1: Overview of three composite T-joint designs used in this study. 


\subsection{Manufacturing}

All three composite T-joint concepts are using the same base material, which is a Saertex carbon fibre non-crimped fabric (NCF) with Tenax HTS fibres in biaxial, triaxial and quadraxial configuration with an aerospace grade epoxy resin. A vacuum-assisted resin infusion process (VAP) was applied before curing at a temperature of $180^{\circ} \mathrm{C}$ and duration of 2 hours. The final parts were then cut and milled to T-specimens of size $150 \mathrm{~mm}$ x $240 \mathrm{~mm}$ x $188 \mathrm{~mm}$. Ultrasonic Cscans and micrographs were taken in order to verify the quality of the specimens and to check for pores or delaminations or other manufacturing-induced predamage.

\subsection{Quasi-static and dynamic testing}

The testing campaign of the T-piece specimens was divided into $0^{\circ}$ tensile tests (T-pull) and $30^{\circ}$ tensile tests (T-bend). The tests were performed both with a quasi-static and a high-speed loading rate of $5 \mathrm{~m} / \mathrm{s}$ and are described in detail in $[8,12]$.

The deformation sequence of all three T-joint designs under quasi-static loading is shown in Figure 2. The D1 specimens fail in a rather brittle manner with a crack initiated in the fillet area in the centre of the specimen, propagating sideward under the spar feet and upward into the spar. In the D2 specimens with integral spar feet the crack initiation is similar in terms of location, peak load and crack propagation. However, the upper plies of the skin are lifted under a higher residual force level and up to much larger displacements. The D3 specimens
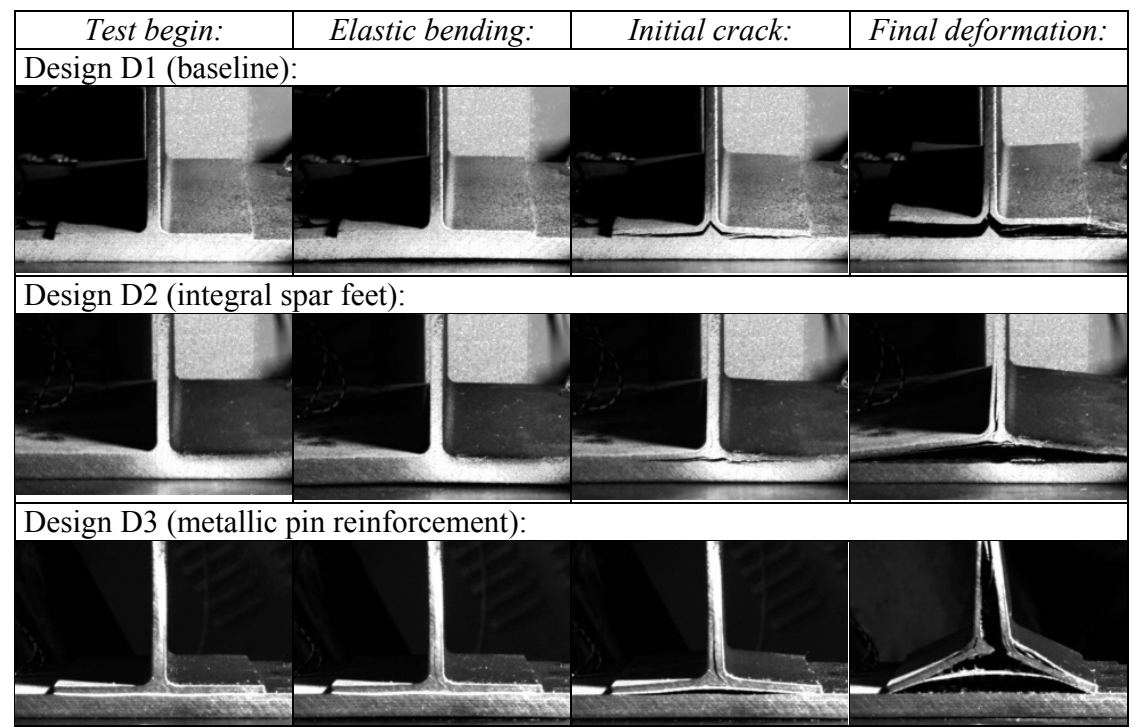

Figure 2: Deformation and failure sequence of all three T-joint designs under $0^{\circ}$ tension. 

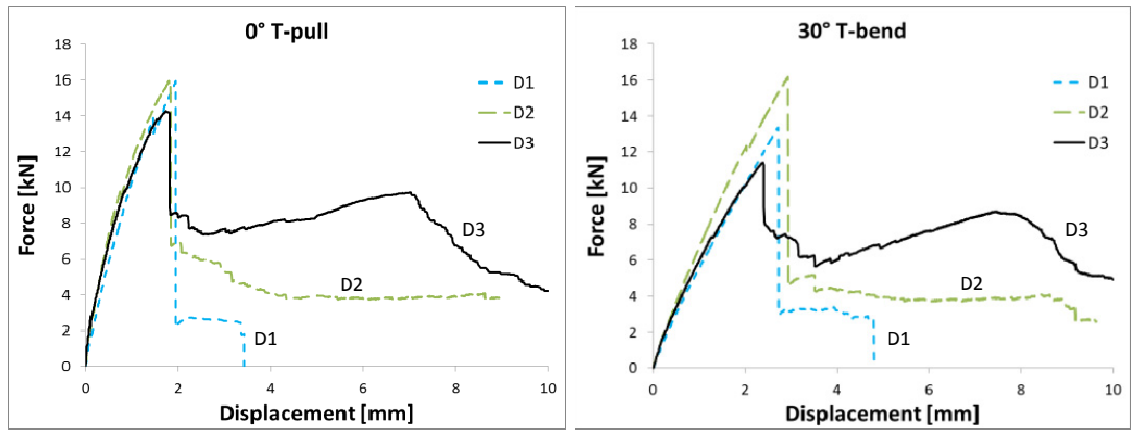

Figure 3: Quasi-static force-displacement results of all three T-joint designs under $0^{\circ}$ and $30^{\circ}$ tension.

show their advantage in the post-damage behaviour, when the metallic pins are either pulled out of the laminate or are loaded under tension until they fail. The residual force level is significantly higher than for all other specimens (Figure 3).

Similar failure modes as in the quasi-static tests were obtained during the high-rate dynamic tests but with a slight increase of peak force levels (see [12]), which is in agreement with other published studies $[14,15]$.

\section{Modelling and HRAM simulation}

\subsection{T-joint model development and validation}

Although T-joint models on micro, meso and macro scale with increasing degree of simplification were developed in LS-Dyna and validated with the experimental T-pull test data (see [12]), only the efficient macro models of the Tjoints were used in the later HRAM simulations.

The macro modelling approach represents the joint behaviour in a specific row of elements in the connection zone of skin and spar with an appropriate material model (Figure 4). Material model MAT123 (*Mat_Modified_Piecewise_Linear_Plasticity_Rate) was used as a promising approach. The user has to define the initial elastic stiffness of the joint, the yield stress for damage initiation, the nonlinear post-damage behaviour as tabular input of stress vs. plastic strain and the plastic strain at failure. The latter three inputs were derived and calibrated in accordance with the experimental forcedisplacement results. Strain rate effects can be incorporated by a simple CowperSymonds yield stress scaling law, by a tabular yield stress scaling law, by tabular input of the stress-strain curve for different strain rates and by tabular input of strain at failure as a function of strain rate.

\subsection{Ballistic impact and HRAM simulation}

The models were applied to ballistic impact and hydrodynamic ram analyses of fuel-filled composite wing tank boxes to assess the mechanical performance 

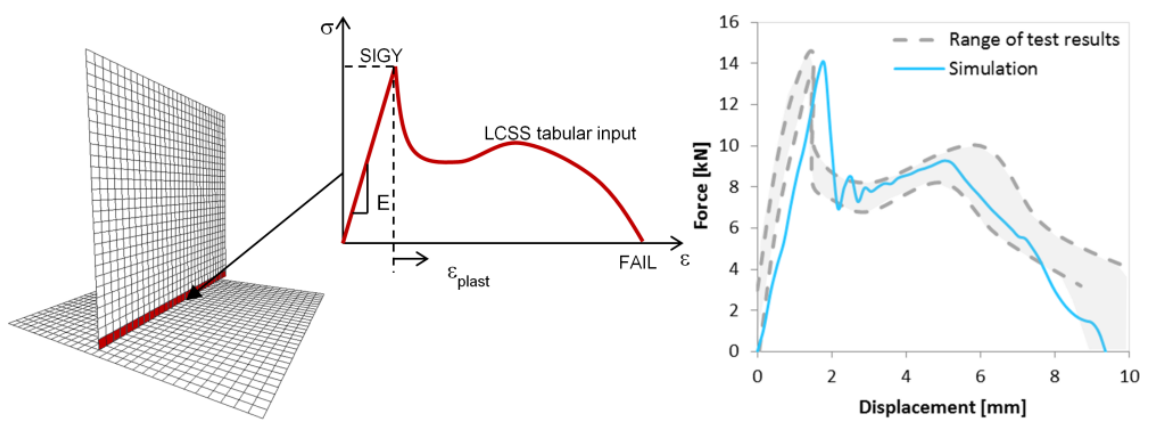

Figure 4: Macro model with homogenised, generic input data for joint failure representation (left) and global force-displacement response of D3 macro model with pin reinforcement (right).

of the three different T-joint designs in a large structural assembly. The structures were generic composite boxes in a 3-cell and 12-cell configuration, representing military aircraft wing segments (Figure 5). These structures were developed, built and used for ballistic impact tests with the focus on the HRAM behaviour in a past project [13]. The models of the 3- and 12-cell wing box were generated in LS-Dyna using the T-joint macro models and the Arbitrary Lagrangian-Eulerian (ALE) approach to model the fluid filling and fluidstructure interaction. Simulating HRAM in fuel tanks with LS-Dyna and ALE is state of the art and has also been performed in numerous studies like in [1-3, 1619]. The projectile was a $4.7 \mathrm{~g}$ steel cylinder, modelled as a rigid body, with an initial velocity of $1600 \mathrm{~m} / \mathrm{s}$. Test data of the previous project [13] in terms of pressure sensor measurements inside the fuel-filled box and post-test damage assessment were used to validate the simulations.

\subsubsection{3-cell box}

After penetration of the composite front skin, a high pressure shock wave is formed and propagates through the fluid with a short-time peak loading of the structure. Afterwards, the projectile is intruding and pushes the fluid aside, leading to a further structural loading with a longer duration. The T-joints of design D1 fail under this load, which is visualised in Figure 5, showing a translucent view of a ballistic impact simulation with the coloured macro elements being eroded under the high pressure load. The other designs D2 and D3 are still intact after the HRAM loading (Figure 6). This is in accordance with the experimental findings of the T-pull tests and supports the performance enhancements by the integrated spar feet and z-reinforcement. Evaluating the final strain levels in the T-joint macro elements reveals that the D2 T-joints reach a maximum of $67 \%$ of their plastic failure strain and the D3 T-joints reach $95 \%$ of their plastic failure strain, which is close to joint failure. Since the upper skinspar junctions were reinforced by rivets in the tested structure to prevent from failure, no macro elements were used at this upper location. 


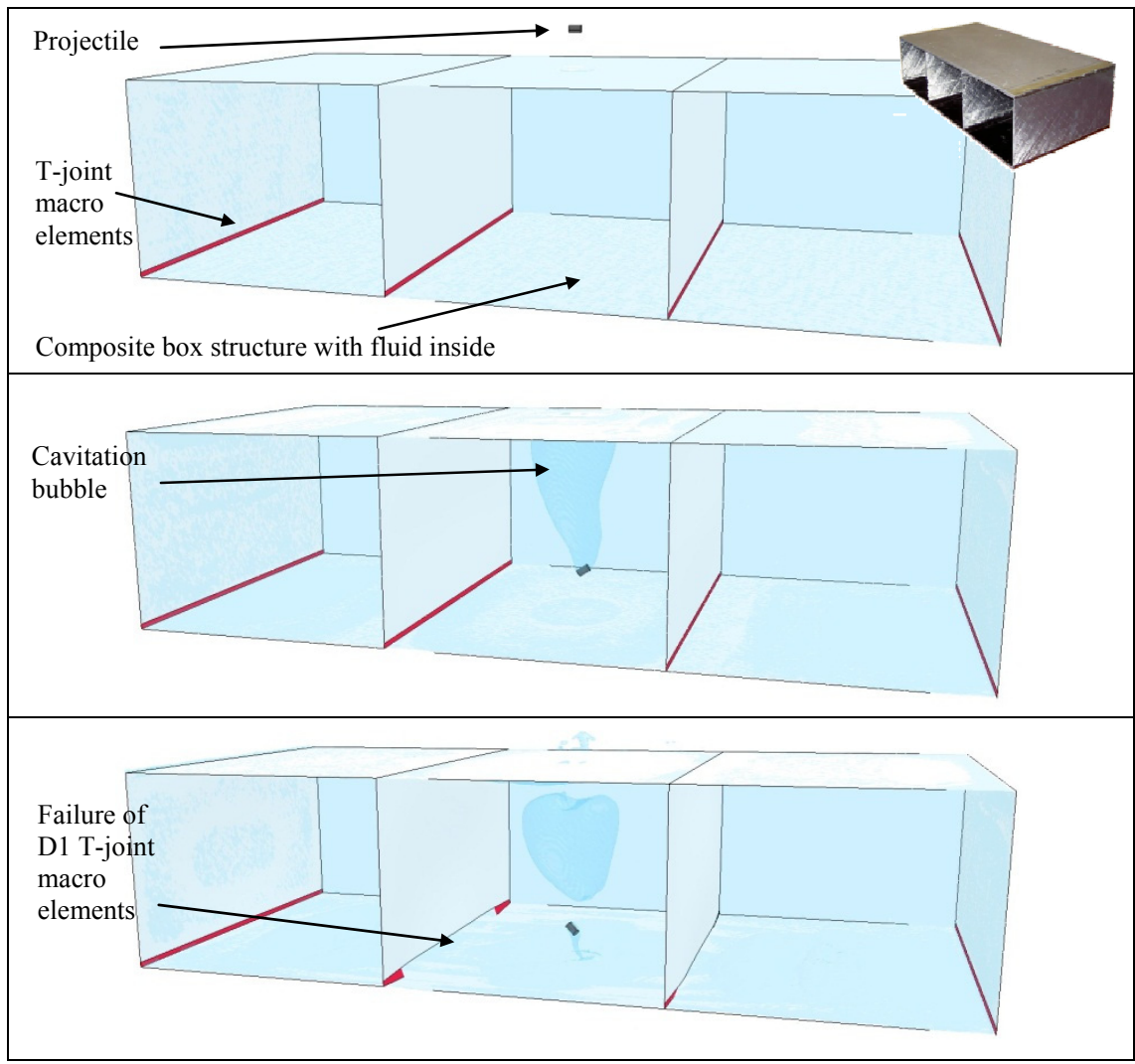

Figure 5: Ballistic impact and hydrodynamic ram simulation of fluid-filled composite 3-cell box (D1).

\subsubsection{2-cell box}

The fluid-filled 12-cell structure of the previous project [13] consists of significantly larger cells than in the previous 3-cell box and is also made of composite material with a metallic frame.

The HRAM simulations with the same projectile and impact velocity as before lead to similar results. The D1 T-joints of the opposite skin fail in the vicinity of the impact location (Figure 7), which is in good agreement with the post-test failure inspection results of the HRAM tests [13]. The other two designs D2 and D3 remain intact again with the D2 macro elements reaching a maximum of $42 \%$ of their plastic failure strain and the D3 joints reaching $21 \%$ of their plastic failure strain. These values are lower than in the 3-cell box study because of the larger cell size. It is interesting to note that the D3 T-joints show the best performance in this load case.

Having this simulation model available, it is easy to perform further parameter studies or load case variations. One example is the increase of the 


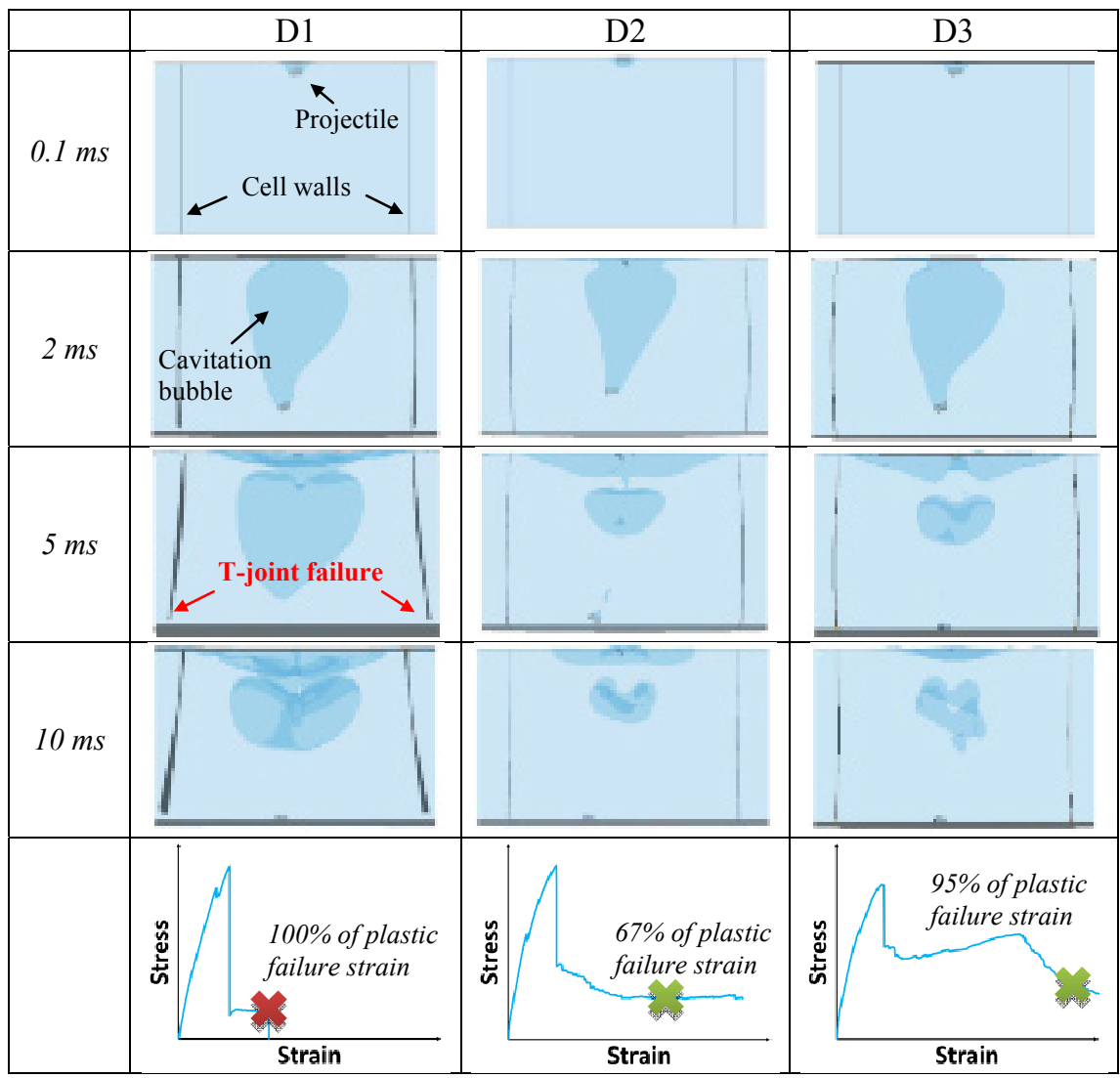

Figure 6: Side view of 3-cell box centre cell under HRAM loading for all three $\mathrm{T}$-joint designs with illustration of maximum strain values reached in T-joint macro elements.

number of projectiles. The load case, which is represented here, is the impact of fragments of a fragment charge that detonates in the vicinity of the military aircraft performing a steep turn. Typically, more than just one fragment is likely to hit the fuel tank skin. The exemplary simulation of four similar projectiles striking the 12-cell structure with identical velocity and identical time of impact is shown in Figure 8. Again, all three T-joint designs were compared by using their macro models. This appears to be a more challenging load case where all three $\mathrm{T}$-joint designs fail, making further T-joint improvements necessary. One option is the use of an advanced toughened resin system in the composite structure. T-joint samples of design D2 with such a resin were manufactured and characterised in [8]. Using these improved properties as input for the T-joint macro model leads to structural integrity without $\mathrm{T}$-joint failure in the 4-projectile impact load case. 


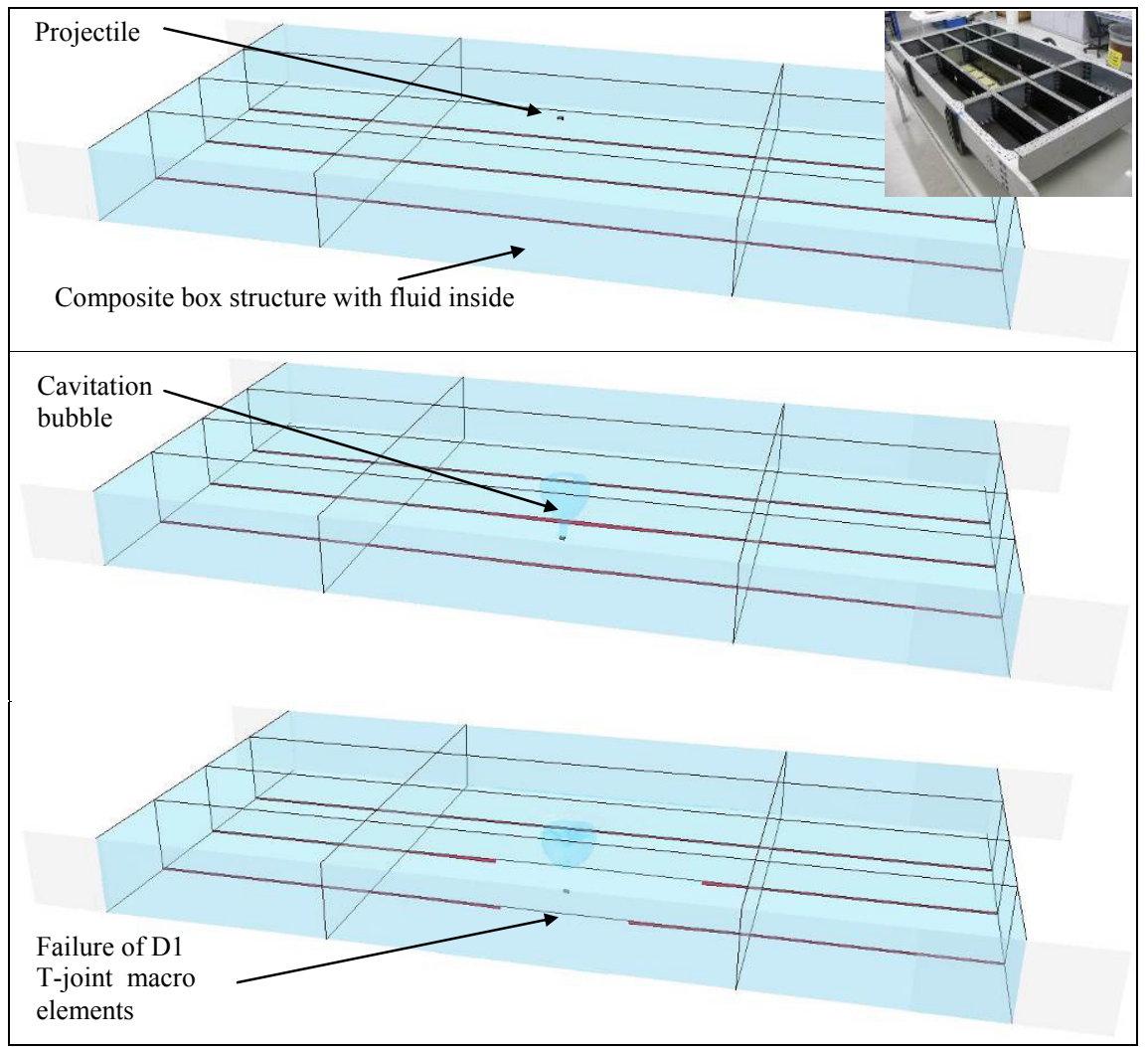

Figure 7: Ballistic impact and hydrodynamic ram simulation of fluid-filled composite 12-cell box (D1), test article photo from [13].

\section{Conclusion}

Three different composite T-joint designs were investigated experimentally and numerically for application in fuel-filled wing tanks under hydrodynamic ram loads. The unreinforced baseline design D1 showed a rather brittle behaviour and failed early with low energy absorption and no residual strength. The integral design D2 led to significant improvements in terms of initial and residual strength increase and structural integrity in the reference HRAM load case. This result was also obtained for the hybrid design D3 with metallic, arrow-shaped z-reinforcements, which showed the best residual strength behaviour.

A promising macro modelling approach for an efficient representation of the T-joint failure behaviour in large models was derived and successfully applied to structural HRAM simulations, making a more detailed and costly modelling of the T-joints needless. The performance of the three designs under HRAM loads in fluid-filled 3-cell and 12-cell boxes under single and multiple projectile impact was assessed and compared. The baseline design failed in all load cases. 


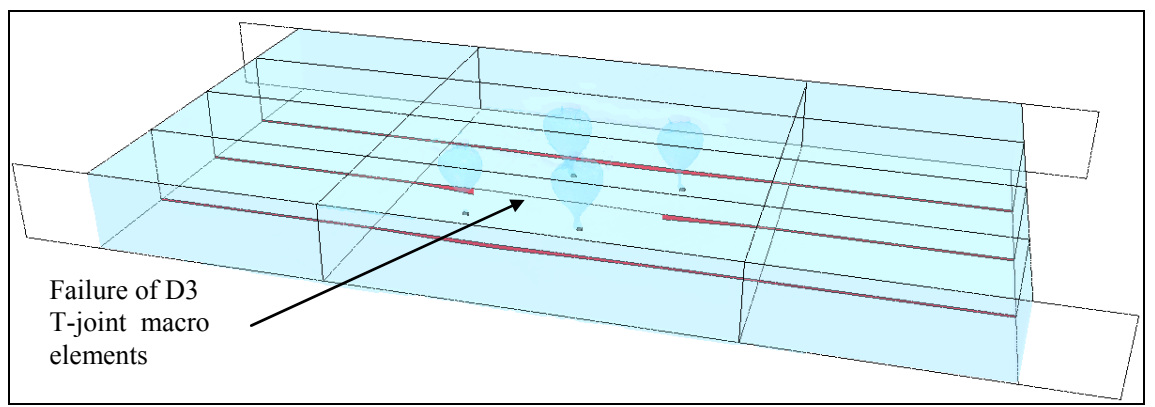

Figure 8: Multiple impact simulation of fluid-filled composite 12-cell box with four projectiles (D3).

Significant improvements could be obtained with the integrated or reinforced designs D2 and D3. However, much potential for further improvements and optimisations on material and design level remains. The modelling methods and simulation models shown here have proven to be a valuable and efficient tool to assess the performance of such $\mathrm{T}$-joint design improvements.

\section{Acknowledgements}

This study was funded by the German Federal Ministry of Defence represented by WIWeB. The financial support is gratefully acknowledged.

\section{References}

[1] Less, C., Hauck, S., Langhans, N., Polis, R., Middendorf, P., Stephani, P., Riedel, W. \& Schacht, V., MALE UAV vulnerability. ESW2006 - 3rd European Survivability Workshop, Toulouse, 2006.

[2] Stephani, P., Middendorf, P. \& Less, C., Numerical analysis of the hydrodynamic ram of a CFRP integral tank. Structures Under Shock and Impact IX, N. Jones (ed.), 2006, WIT Press, pp. 45-55.

[3] Varas, D., Zaera, R. \& Lopez-Puente, J., Numerical modelling of partially filled aircraft fuel tanks submitted to hydrodynamic ram. Aerospace Science and Technology, 16(1), pp. 19-28, 2012.

[4] Santini, P., Palmieri, D. \& Marchetti, M., Numerical simulation of fluidstructure interaction in aircraft fuel tanks subjected to hydrodynamic ram penetration. ICAS 1998 - 21st Congress of International Council of the Aeronautical Sciences, Melbourne, 1998.

[5] Wierzbicki, T. \& Moussa, N.A., Deformation and rupture of an aircraft fuel tank under hydraulic ram pressure loading. 63rd Shock and Vibration Symposium, Las Cruces, NM, 1992.

[6] Lundstrom, E.A., Fuel cell structural response to hydraulic ram. In: Shock and Wave Propagation, PVP-Vol. 134, ASME, pp. 39-51, 1988. 
[7] Helwig, C.H.M., Sachs, G.W. \& Seidel, K.G.K., Numerical investigation of hydraulic ram effects in fuel tanks. 10th International Symposium on Ballistics, San Diego, CA, 1987.

[8] Heimbs, S., Mierzwa, A., Duwensee, T., Nogueira, A.C., Breu, C., May, M., Less, C. \& Wolfrum, J., Investigation of static and dynamic failure behaviour of composite T-joints. Composites 2013, 4th ECCOMAS Thematic Conference on the Mechanical Response of Composites, Azores, 2013.

[9] Moshier, M.A., Hinrichsen, R.L., Czarnecki, G.J. \& Cook, N.L., Testing composite joints under high energy hydrodynamic ram conditions. 45th AIAA/ASME/ASCE/AHS/ASC Structures, Structural Dynamics and Materials Conference, Palm Springs, CA, 2004.

[10] Czarnecki, G.J., Hinrichsen, R. \& Maxson, M., Joint resistance to ram. U.S. Air Force T\&E Days, Nashville, TN, 2005.

[11] Nogueira, A.C., Drechsler, K. \& Hombergsmeier, E., Analysis of the static and fatigue strength of a damage tolerant 3D-reinforced joining technology on composite single lap joints. 53rd AIAA/ASME/ASCE/AHS/ASC Structures, Structural Dynamics and Materials Conference, Honolulu, HI, 2012.

[12] Heimbs, S., Nogueira, A.C., Hombergsmeier, E., May, M. \& Wolfrum, J., Failure behaviour of composite T-joints with novel metallic arrow-pin reinforcement. Composite Structures, 110, pp. 16-28, 2014.

[13] EUCLID RTP 3.32 Low vulnerability composite structures for military aircraft, Synthesis report RTP-3.32/7/TR/EADS-D/045/D, EADS, Ottobrunn, 2007.

[14] Herkt, M., Middendorf, P., Less, C., Riedel, W., Maier, G. \& Drechsler, K., Dynamic strength testing of 3D-reinforced T-joints. ICAS $2006-25$ th Congress of International Council of the Aeronautical Sciences, Hamburg, 2006.

[15] Renze, S.P., Carnegie, S.W. \& Sandow, F., Experimental evaluation of survivable composite structural concepts. 37th AIAA/ASME/ASCE/AHS/ ASC Structures, Structural Dynamics and Materials Conference and Exhibit, Salt Lake City, UT, 1996, pp. 39-46.

[16] McCallum, S.C. \& Townsend, D.D., Simulation of hydrodynamic ram and liquid aeration. 5th European LS-DYNA Users Conference, Birmingham, UK, 2005.

[17] Poehlmann-Martins, F., Gabrys, J. \& Souli, M., Hydrodynamic ram analysis of non-exploding projectile impacting water. ASME Pressure Vessels and Piping Division Conference, Denver, CO, 2005.

[18] Seddon, C.M. \& Moatamedi, M., Fluid structure interaction of fuel tank impact. ler Colloque du GDR Interactions Fluide-Structure, Sophia Antipolis, France, 2005.

[19] Sparks, C.E., Hinrichsen, R.L. \& Friedmann, D., Comparison and validation of smooth particle hydrodynamic (SPH) and coupled Euler Lagrange (CEL) techniques for modeling hydrodynamic ram. 46th AIAA/ASME/ASCE/AHS/ASC Structures, Structural Dynamics and Materials Conference, Austin, TX, 2005. 